\title{
Bronchogenic cysts: clinicopathological presentation and treatment
}

\author{
S. Aktoğu*, G. Yuncu**, H. Halilçolar*, S. Ermete+, T. Buduneli**
}

Bronchogenic cysts: clinicopathological presentation and treatment. S. Aktoğu, G. Yuncu, H. Halilcolar, S. Ermete, T. Buduneli. CERS Journals Ltd 1996.

ABSTRACT: The aim of this study was to evaluate the preoperative and operative presentations of one paediatric and 30 adult patients with bronchogenic cyst of the mediastinum $(n=11)$ and lung $(n=20)$.

At initial presentation, six patients were asymptomatic and 25 were symptomatic. The mean age of asymptomatic and symptomatic patients was 25 and 33 yrs, respectively. Six patients presented with complications, including superior vena cava syndrome, tracheal compression, pneumothorax, pleurisy and pneumonia. Two patients who were asymptomatic when initially observed eventually needed surgery because of the development of symptoms or enlargement of the cyst size. In one patient, the cyst was not seen on the chest radiograph but appeared as a lobulated nodule of 2 cm diameter in a chest computerized tomography (CT) scan. Operative difficulties were encountered in 13 patients, all of whom were symptomatic preoperatively.

In conclusion, life-threatening complications occurred in these patients. Despite various diagnostic studies, definitive tissue diagnosis was established only by means of surgical excision. The frequency of operative difficulties in symptomatic cysts was higher than those of asymptomatic cysts. Surgery may be considered as the treatment of choice even when the cyst is asymptomatic, since complications are not uncommon. Eur Respir J., 1996, 9, 2017-2021.
Depts of *Pulmonary Medicine, **Thoracic Surgery, and +Pathology, Chest Diseases Teaching Hospital, Izmir, Turkey.

Correspondence: S. Aktoğu

Izmir Göğüs Hastalıklrı Hastanesi

35110 Izmir

Turkey

Keywords: Bronchogenic cysts lung cysts

mediastinum

Received: October 271995

Accepted after revision June 81996
Bronchogenic cysts, commonly located in the mediastinum or lung parenchyma, arise from abnormal budding of the primitive tracheobronchial tube. The location of the cyst depends on the embryological stage of development at which the anomaly occurs. When this abnormal buddings occurs during early development, the cyst tends to be located along the tracheobronchial tree. Cysts that arise later are more peripheral and may be located within the lung parenchyma $[1,2]$.

Past reports have emphasized that a bronchogenic cyst is usually asymptomatic and presents as an incidental finding on the chest roentgenogram [3,4]. Conversely, more recent series suggest that the majority of adults with bronchogenic cysts ultimately become symptomatic $[2,5$, 6]. However, each of these retrospective series, including our own, concerns a selected population which was treated surgically. The actual natural history and percentage of asymptomatic bronchogenic cysts in the adult are not known because of the absence of long-term follow-up of a large group of patients with asymptomatic cysts. Despite diagnostic studies, including chest computerized tomography (CT) scan, magnetic resonance imaging, and fine needle aspiration (FNA), definitive tissue diagnosis can only be established by means of surgical excision. The purpose of this study was to evaluate the demographic, clinical, radiological, operative and pathological presentations of such cysts.

\section{Material and methods}

The medical records of 31 patients who underwent surgical excision of histologically confirmed bronchogenic cysts at the Chest Diseases Teaching Hospital, Izmir, during the period 1975-1994, were reviewed. This hospital serves mainly as a referral centre to the city of Izmir and the surrounding Aegean regions, with 800 beds for chest diseases and thoracic surgery. This retrospective investigation included demographic data, presenting symptom(s), roentgenographic, surgical and pathological findings, and preoperative and operative complications. Radiological evaluation consisted of posteroanterior and lateral chest roentgenographs, CT scans, and chest tomograms. The uniform CT density within a range -10 to +10 Hounsfield units (HU) was accepted as a CT density close to that of water. Anatomical locations of bronchogenic cysts were determined based on radiological and operative findings. Histopathological diagnosis was established by review of material obtained from operation. The cysts without respiratory epithelium were excluded from the study. Clinical and pathological data were combined to confirm the intrapulmonary bronchogenic cysts.

\section{Analysis}

Mann-Whitney U-test was used to compare the ages of symptomatic and asymptomatic patients.

\section{Results}

\section{Demographic findings and locations}

Over a 19 year period (1975-1994), one paediatric and 30 adult patients underwent surgical excision of bronchogenic cysts of the mediastinum $(n=11)$ and lung $(n=20)$. Of these, 14 were female and 17 were male, aged 4-69 
yrs (mean 32 yrs). The locations of mediastinal bronchogenic cysts were paratracheal (2), subcarinal (2), right hilar (2), left hilar (1), and paraoesophageal (4). Nine intraparenchymal cysts were located in the lower lobes (right lower lobe (6), left lower lobe (3)). They were also found in any of the other lobes (right upper lobe (3), left upper lobe (3), middle lobe (3), and lingula (2)).

\section{Clinical presentations}

Six patients were asymptomatic at initial presentation. Their mean age was 25 yrs. In these patients, the cysts were found incidentally during pre-employment or premilitary screening. Two of the cysts were mediastinal and four were intraparenchymal.

Twenty five patients were symptomatic at initial presentation. Their mean age was 33 yrs. No significant age difference was found between symptomatic and asymptomatic groups $(\mathrm{p}=0.23)$. These patients had symptom(s) for periods of time ranging from 1 week to 12 yrs before surgery. The majority had more than one symptom. The most common symptoms were cough, purulent sputum, chest pain, fever, dyspnoea, anorexia and/or weight loss, and haemoptysis.

Six patients presented with serious complications. One patient with mediastinal bronchogenic cyst was referred with superior vena cava syndrome and tracheal compression (fig. 1), and another with intraparenchymal bronchogenic cyst presented with pneumothorax. Other major complications were pleurisy and pneumonia. In two patients, intrapulmonary bronchogenic cysts were associated with coexisting diseases. In a 19 year old male patient, a bronchogenic cyst in the left upper lobe was found in association with a cylindrical bronchiectasis in the left lower lobe. In a 32 year old female patient, a carcinoid tumour originating from the right upper lobe bronchus was found in association with a bronchogenic cyst in the right lower lobe. In these two patients, no complication such as pleurisy or pneumonia was found and their complaints were excluded from the classification of symptoms.

Surgical resection was eventually performed in two initially asymptomatic patients because of the development of symptoms or enlargement of cyst size over a period of 4-8 yrs.

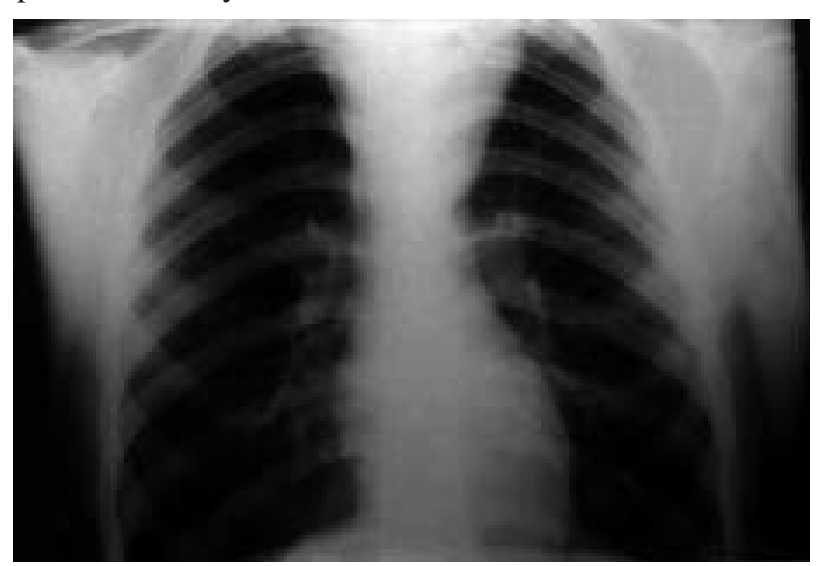

Fig. 1. - Posteroanterior chest radiograph showing enlargement of the superior mediastinum because of a bronchogenic cyst originating from the anterolateral wall of the trachea. This patient was referred with superior vena cava syndrome and tracheal compression.
Table 1. - Roentgenographic presentations in the mediastinal and pulmonary bronchogenic cyst

\begin{tabular}{lccc}
\hline & $\begin{array}{c}\text { MBC } \\
(\mathrm{n}=11)\end{array}$ & $\begin{array}{c}\text { PBC } \\
(\mathrm{n}=20)\end{array}$ & $\begin{array}{c}\text { Total } \\
(\mathrm{n}=31)\end{array}$ \\
\hline Well-defined mass & 11 & 7 & 18 \\
Air-fluid level & 0 & 7 & 7 \\
Thin-walled cystic cavity & 0 & 5 & 5 \\
Pneumonia & 2 & 2 & 4 \\
Pleurisy & 1 & 0 & 1 \\
Pneumothorax & 0 & 1 & 1 \\
\hline
\end{tabular}

MBC: mediastinal bronchogenic cyst; PBC: pulmonary bronchogenic cyst.

\section{Diagnostic studies}

For diagnostic purpose, various radiological tests were performed, such as posteroanterior (PA) and lateral chest roentgenographs (31), chest tomogram (10), CT scan (9), and barium swallow (2). Chest roentgenograph was abnormal but nondiagnostic in 30 patients. In one patient, the intrapulmonary cyst was not seen on the chest radiograph, but CT scan showed a lobulated nodule with a diameter of $2 \mathrm{~cm}$ in the same patient. Table 1 shows the most common presentations of bronchogenic cysts on the chest radiograph. Bronchogenic cysts generally appeared as a well defined mass of homogeneous density. Intrapulmonary cysts also presented as an air-filled cyst or showed an air-fluid level.

At CT scan (fig. 2), classical signs of a benign cystic structure were found in eight patients. Based on the CT appearance, however, a bronchogenic cyst was considered in the differential diagnosis of only four patients. CT findings of the nine patients are presented in table 2. Prior to the availability of CT scan, chest tomograms were performed as complementary to positive chest roentgenographic findings. Combining all radiological methods, a bronchogenic cyst was considered in the preoperative differential diagnosis of nine patients.

\section{Surgery and histopathology}

In 30 patients, the operative approach was a posterolateral thoracotomy. One mediastinal bronchogenic cyst

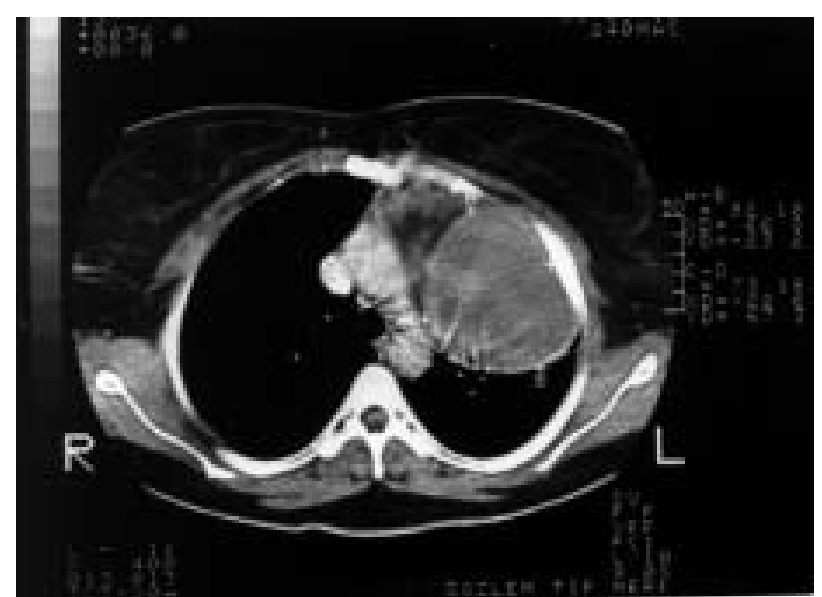

Fig. 2. - Computed tomography (CT) section showing a $9 \times 7 \mathrm{~cm}$ cystic lesion with a well-defined wall and $\mathrm{CT}$ attenuation measuring 0 Hounsfield units (HU). 
Table 2. - CT scan findings in eight patients with bronchogenic cyst

\begin{tabular}{lcccc}
\hline Water density & $\begin{array}{c}\text { Thin-walled } \\
\text { cystic cavity } \\
\mathrm{n}=3\end{array}$ & $\begin{array}{c}\text { Air-fluid } \\
\text { level } \\
\mathrm{n}=1\end{array}$ & $\begin{array}{c}\text { Solid } \\
\text { mass } \\
\mathrm{n}=1\end{array}$ \\
\hline PBC & 1 & 3 & 1 & 1 \\
MBC & 3 & 0 & 0 & 0
\end{tabular}

PBC: pulmonary bronchogenic cyst; MBC: mediastinal bronchogenic cyst; CT: computed tomography; HU: Hounsfield units.

originating from the anterolateral wall of the trachea was resected via a median sternotomy. Complete surgical excision was performed in nine cases of mediastinal cysts. In two patients, a part of the cyst wall was left attached to the great vascular structures due to extensive pericystic fibrotic adhesions. These two patients were followed-up over a period of 3-5 yrs, and no recurrence occured. In one patient, excision of the cyst with middle lobectomy was performed because of dense pulmonary adhesions and insufficient lung expansion. Another patient required tracheal resection and Teflon patch, with excision of the "dumbbell"-shaped cyst. Intrapulmonary cysts necessitated segmental resection (11), lobectomy (4), or wedge resection (3). In two patients, pneumonectomy was required due to coexisting disease. Surgical resection was complicated by pulmonary and vascular

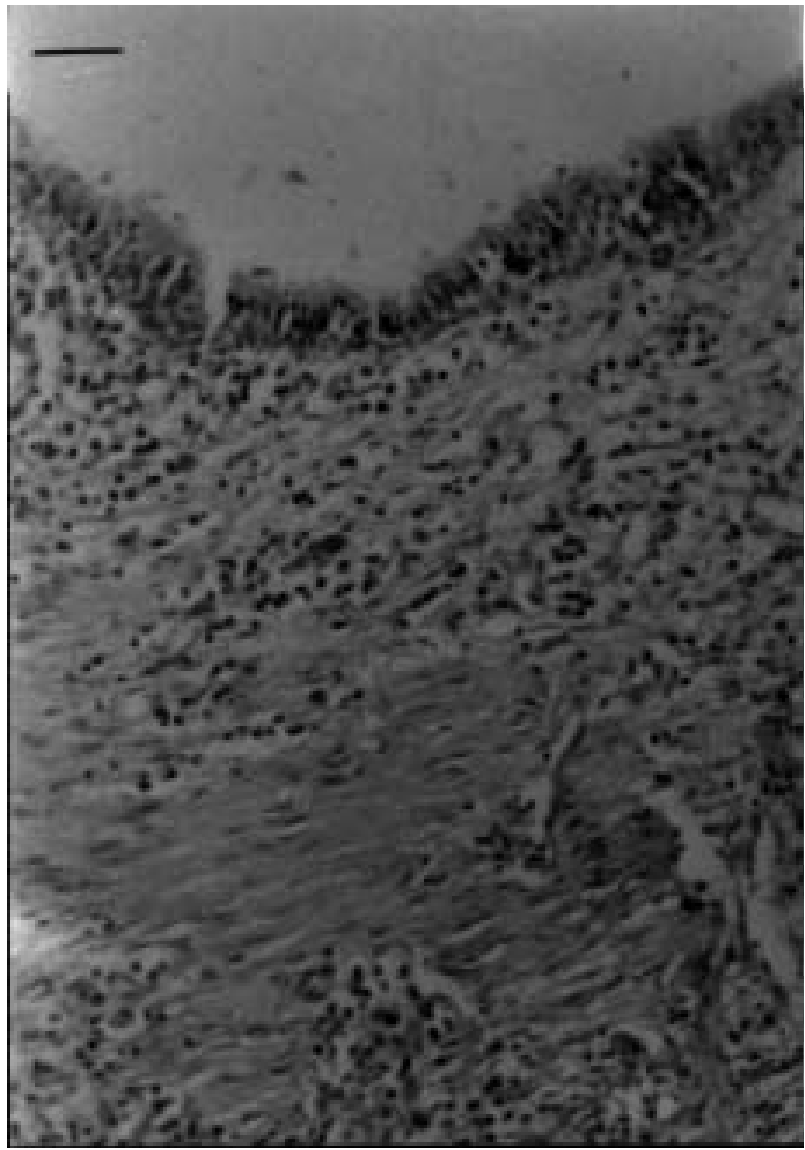

Fig. 3. - Histology of the mediastinal cyst wall showing pseudostratified columnar type epithelium. Smooth muscle is seen beneath the epithelial lining. (Haematoxylin and eosin stain; Scale bar $=100 \mu \mathrm{m}$ ). compressions (6), as well as vascular (3), tracheobronchial (3), pulmonary (3), pleural (3), mediastinal and diaphragmatic adhesions (1). There were marked adhesions between chest wall and cyst in four patients. Two other patients had a fistula between the cyst and the airway. Thus, operative difficulties due to either dense pericystic adhesions or fistulization were encountered in 13 symptomatic patients. Three intraparenchymal cysts were infected without fistulizations, and one mediastinal cyst was frankly haemorrhagic. The complaints resolved following surgery in all patients in the follow-up period of 2-10 yrs.

All cysts were lined by ciliated columnar epithelium. The mucosa contained chronic inflammatory infiltrates (8), necrosis (4), and focal areas of squamous metaplasia (2). Vascular proliferation was seen in nine cysts, and other histological findings included; bronchial cartilage (5), connective tissue (7), bronchial gland (3), and smooth muscle (3) (fig. 3). While bronchial cartilages and glands were found in the walls of mediastinal cysts strands of smooth muscle were observed in the walls of two intrapulmonary cysts. There were also connective tissue (6), and vascular proliferation (5) in the intrapulmonary cysts.

\section{Discussion}

Bronchogenic cysts are found most frequently along the tracheobronchial tree in the mediastinum or within the lung parenchyma. Rarely, the cysts have occurred in other locations, including cutaneous [7] and subcutaneous tissues [8], neck [9], pericardium [10], diaphragm [11], abdomen [12], and the intramedullar part of the spine [13]. They have also been reported to extend from the mediastinum through the diaphragm into the abdomen as dumbbell cysts [14]. The relative occurrence rates of intrapulmonary and mediastinal bronchogenic cysts are controversial. Studies by DiLorenzo et al. [1], St. Georges et al. [2], and Patel et al. [5] indicate that the frequency of mediastinal bronchogenic cysts is greater, whereas other series, including our own, reflect a higher frequency of cysts with intrapulmonary location [15-18]. These discrepancies may result from the difficulties of differential diagnosis between intrapulmonary bronchogenic cysts and other acquired lesions.

There are differences in the published series with respects to symptomatology and treatment of these cysts. Some studies have reported bronchogenic cysts frequently presenting as an incidental radiological finding in the adult; these cysts were of little clinical importance and could be followed up [3, 4]. The largest and most recent series have reported symptoms, complications, or both with the majority of bronchogenic cysts. Surgical excision is therefore recommended even for asymptomatic cysts, to prevent complications and operative difficulties $[2,5,6]$. In the present series, 25 cysts were symptomatic. Although no significant difference was found, the mean age of symptomatic patients was slightly higher than that of asymptomatics. The presenting symptoms may indicate compression or irritation of major airways by the cyst, infection of the cyst, and pneumonia in the adjacent parenchyma. Six patients had serious complications, including superior vena cava syndrome, tracheal 
compression, pneumothorax, pleurisy, and pneumonia. RAMMOHAN et al. [19], and BANKOFF et al. [20] have each reported a patient with superior vena cava syndrome due to mediastinal bronchogenic cyst. MATZINGER et al. [21] reported a case of intrapulmonary bronchogenic cyst in a 16 year old girl presenting with pneumothorax. Other reported complications are pleural effusion [22, 23], arrhythmias [24], stenosis of the pulmonary artery [25], unilateral ventilation-perfusion defect [26], pericardial and cardiac tamponade [27], carcinomatous [28] or sarcomatous transformation [29], and giant tension bronchogenic cyst [30].

Intrapulmonary bronchogenic cysts generally present as one of three different patterns on the chest radiograph. If no communication is present between the bronchus and parenchyma, the cyst appears as a homogeneous mass with a density of water or a nodule. Differential diagnosis includes benign and malignant tumours, hydatid cysts, granulomas, hamartomas, vascular malformations and lung sequestration. When communication is established with the bronchial tree, the cyst presents as airfilled or contains an air-fluid level. Such a cyst may be confused with lung abscesses, complicated hydatid cysts, infected bullae, cavities resulting from tuberculosis, fungal diseases, carcinoma, or infarctions [5, 17, 30, 31]. Mediastinal bronchogenic cysts usually present as ovoid or round, well-defined masses of homogeneous water density on the chest radiograph $[31,32]$. Occasional airfluid levels or peripheral calcification may be found $[5$, 32]. The differential diagnosis includes aneurysms, lymphadenopathy, thyroid goitre, cystic hygroma, neurogenic tumours, lymphoma, teratoma, metastatic tumour, enteric, oesophageal duplication or pericardial cysts $[5,17]$.

CT provides the optimal demonstration of cyst location, morphology, and contents. Generally, bronchogenic cysts have homogeneous CT attenuation and water density. However, because of their protein and calcium contents and presence of infection, the cysts may have attenuation values as high as $120 \mathrm{HU}[33,34]$.

Based on the CT appearance, a bronchogenic cyst was considered in the differential diagnosis of four patients. Combining all radiological modalities, a bronchogenic cyst was considered in the preoperative differential diagnosis of nine patients. This value was lower than those of other series [5]. The differential diagnosis based on the chest radiograph alone has been reported to range $20-77 \%$ [32]. Various factors may contribute to this high rate of preoperative diagnostic uncertainty. Presentations with severe complications, unusual radiological findings such as pneumothorax, pneumonia and pleurisy, the common occurrence of hydatid cysts and pulmonary tuberculosis in Turkey, and the unavailibity of fine needle aspiration (FNA) may have a negative effect on preoperative differential diagnosis.

Because of dense pericystic adhesions to adjacent structures, surgical resection may be difficult, especially in the preoperatively symptomatic patients. ST GEORGES et al. [2] found that major operative difficulties or intraoperative complications were encountered in 29 of 86 symptomatic patients. PATEL et al. [5] reported a trend toward greater operative and more operative and postoperative complications in the symptomatic patients. In the present series, operative difficulties resulting from dense pericystic adhesions or fistulization were described in 13 symptomatic patients. In intrapulmonary bronchogenic cysts, segmental or lobar resections are required procedures. In two patients, pneumonectomy was performed due to coexisting diseases. Although imaging methods and FNA are the most useful diagnostic studies, surgical intervention is important because definitive tissue diagnosis can only be established by means of surgical excision. Some investigators have advocated that transbronchial [35, 36], transoesophageal [37], and percutaneous [22, 38] FNA are useful procedures for diagnosis and management. This intervention has also been performed to remove the contents of a cyst which had obstructed the major airways during induction of anaesthesia [39]. However, recurrences or complications may be observed during or after FNA [40-42]. If bronchogenic cysts are drained or partially excised, longterm follow-up is indicated to detect cyst recurrence [41, 42].

Microscopically, the cysts contain one or more of the tissues that are normally found in the trachea or bronchi. Characteristically, they are lined with ciliated, pseudostratified, columnar epithelium. In portions of the cyst, squamous metaplasia may occur, or the epithelium as well as cilia may be absent. The walls of the cyst consist of fibrous connective tissue, which commonly, but not necessarily, contains glands, hyaline cartilage, smooth muscle, elastic fibres, and nerve trunks, either alone or varying combinations [17]. Pathologically, it may be difficult to separate an acquired lesion from an intrapulmonary bronchogenic cyst, since an acquired cyst may occasionally epithelialize with pseudostratified ciliated epithelium. The absence of associated parenchymal and bronchial inflammation and the lack of a clinical history of pulmonary inflammation are suggestive of a bronchogenic cyst [30, 31]. Although, in two patients, bronchogenic cysts were associated with other diseases, we believe this was coincidental, since the cysts were noninfected and uncomplicated, contained mucoid fluid, and did not communicate with the tracheobronchial tree. Moreover, cysts and coexisting diseases were localized in different lobes and no evidence was found of pericystic paranchymal inflamation or fibrosis.

In conclusion, asymptomatic patients with bronchogenic cysts may ultimately become symptomatic cases, and in time may develop life-threating complications. Definitive tissue diagnosis is usually available only after surgical excision. In symptomatic patients, operative difficulties are more frequently encountered. Based on these data, we suggest that bronchogenic cysts should be treated surgically and that a conservative approach is not recommended.

\section{References}

1. DiLorenzo M, Collin P, Vaillancourt R, Duranceau A. Bronchogenic cysts. J Pediatr Surg 1989; 24(10): 988991.

2. St. Georges R, Deslauriers J, Duranceau A, et al. Clinical spectrum of bronchogenic cysts of the mediastinum and lung in the adult. Ann Thorac Surg 1991; 52: 6-13.

3. Maier HC. Bronchogenic cysts of the mediastinum. Ann Surg 1948; 127: 476-502.

4. Fontenelle LJ, Armstrong RG, Stanford W, Lindberg EF, Dooley BN. The asymptomatic mediastinal mass. Arch Surg 1971; 102: 98-102. 
5. Patel SR, Meeker DP, Biscotti CV, Kirby TJ, Rice TW. Presentations and management of bronchogenic cysts in the adult. Chest 1994; 106: 79-85.

6. Sirivella S, Ford WB, Zikria EA, Miller WH, Samadani SR, Sullivan ME. Foregut cysts of the mediastinum: results in 20 consecutive surgically treated cases. J Thorac Cardiovasc Surg 1985; 90: 776-782.

7. Tresser NJ, Dhams B, Berner JJ. Cutaneous bronchogenic cyst of the back: a case report and review of the literature. Pediatr Pathol 1994; 14: 207-212.

8. Bagwell CE, Schiffman RJ. Subcutaneous bronchogenic cysts. J Pediatr Surg 1988; 23: 993-995.

9. Riquet M, Choubrac P, Molinier H, Carnot F, Debesse B. Kyste tracheogenique aerien cervical: a propos de 2 observations. Rev Pneumol Clin 1985; 41: 157-162.

10. Gomes MN, Hufnagel CA. Intrapericardial bronchogenic cysts. Am J Cardiol 1975; 36: 817-822.

11. Buddington TW. Intradiaphragmatic cyst. Ninth reported case. N Engl J Med 1957; 257: 613-614.

12. Coselli MP, Ipolyi P, Bloss RS, Diaz RF, Fitzgerald JB. Bronchogenic cysts above and below the diaphragm: Report of eight cases. Ann Thorac Surg 1987; 44: 491-494.

13. Duthel R, Brunon J, Michel D, Boucheron S. Kyste bronchogenique intramedullaire. A propos d'un cas. Discussion du syndrome d'adhesion syndromes. Neurochirurgie 1983; 29: $155-160$.

14. Amendola MA, Shirazi KK, Brooks J, Agha FP, Dutz W. Transdiaphragmatic bronchopulmonary foregut anomaly: "Dumbbell" bronchogenic cyst. AJR 1982; 138: $1165-1167$.

15. Ramenofsky ML, Leape LL, McCauley RG. Bronchogenic cyst. J Pediatr Surg 1979; 14: 219-224.

16. Dogan R, Çetin G, Moldibi B, et al. Les kystes bronchogeniques pulmonaires et mediastinaux. Rev Mal Respir 1988; 5: 123-127.

17. Rogers LF, Osmer JC. Bronchogenic cyst: a review of 46 cases. AJR 1964; 91: 273-293.

18. Schmidt FE, Drapanas T. Congenital cystic lesions of the bronchi and lungs. Ann Thorac Surg 1972; 14: 650-657.

19. Rammohan G, Berger HW, Lajam F, Buhain W. Superior vena cava syndrome caused by bronchogenic cyst. Chest 1975; 68: 599-601.

20. Bankoff MS, Daly BD, Johnson HA, Carter BL. Bronchogenic cyst causing superior vena cava obstruction: CT appearance. J Comput Assist Tomogr 1985; 9: 951952.

21. Maťzinger MA, Matzinger FR, Sachs HJ. Intrapulmonary bronchogenic cyst: spontaneous pneumothorax as the presenting symptom. AJR 1992; 158: 987-988.

22. Adam A, MacSweeney JE, Whyte MK, Smith PL, Ind PW. CT-guided extrapleural drainage of bronchogenic cyst. J Comput Assist Tomogr 1989; 13: 1065-1068.

23. Khalil A, Carette MF, Milleron B, Grivaux M, Bigot JM. Bronchogenic cyst presenting as mediastinal mass with pleural effusion. Eur Respir J 1995; 8: 2185-2187.

24. Watson AJ, Chaudhary BA. Cardiac arrhythmias and abnormal chest roentgenogram. Chest 1987; 92: 335336.
25. Harris M, Woo-Ming MO, Miller CG. Acquired pulmonary stenosis due to compression by a bronchogenic cyst. Thorax 1973; 28: 394-398.

26. Berkowitz KA, Fleischman JK, Smith RL. Bronchogenic cyst causing a unilateral ventilation-perfusion defect on lung scan. Chest 1988; 93: 1292-1293.

27. Kirvan WO, Walbaum PR, McCormack RJM. Cystic intrathoracic derivatives of the foregut and their complications. Thorax 1973; 28: 424-428.

28. Miralles Lozano F, Gonzales-Martinez B, Luna More S, Valencia Rodriquez A. Carcinoma arising in a calcified bronchogenic cyst. Respiration 1981; 42: 135-137.

29. Brehand A, Kravitz CH. Sarcoma arising in a bronchogenic cyst. Surgery 1951; 24: 142-143.

30. Tarpy SP, Komfeld H, Moroz K, Lazar HL. Unusual presentation of a large tension bronchogenic cyst in an adult. Thorax 1993; 48: 951-952.

31. Fraser RB, Pare JAB, Pare PD, Fraser RS, Genereux GP. Pulmonary abnormalities of developmental origin. Vol. 2. In: Diagnosis of Diseases of the Chest. Philadelphia; W.B. Saunders, 1989; pp. 675-773.

32. Haddon MJ, Bowen A. Bronchopulmonary and neurenteric forms of foregut anomalies: imaging for diagnosis and management. Radiol Clin North Am 1991; 29(2): 241-254.

33. Kuhlman JE, Fishman EK, Wang KP, Zerhouni EA, Siegelman SS. Mediastinal cysts: diagnosis by CT and needle aspiration. AJR 1988; 150: 75-78.

34. Mendelson DS, Rose JS, Efremidis SC, Kirschner PA, Cohen BA. Bronchogenic cysts with high CT numbers. AJR 1983; 140: 463-465.

35. Schwartz DB, Beals TF, Wimbish KJ, Hammersley JR. Transbronchial fine needle aspiration of bronchogenic cyst. Chest 1985; 88: 573-575.

36. Schwartz AR, Fishman EK, Wang KP. Diagnosis and treatment of a bronchogenic cyst using transbronchial needle aspiration. Thorax 1986; 41: 326-327.

37. VanDam J, Rice TW, Sivak MV. Endoscopic ultrasonography and endoscopically guided needle aspiration for the diagnosis of upper gastrointestinal tract foregut cysts. Am J Gastroenterol 1992; 87: 762-765.

38. Zimmer WD, Kamida CB, McGough PF, Rosenow EC. Mediastinal duplication cyst: percutaneous aspiration and cystography for diagnosis and treatment. Chest 1986; 90 : 772-773.

39. McDougall JC, Fromme GA. Transcarinal aspiration of a mediastinal cyst to facilitate anesthetic management. Chest 1990; 97: 1490-1492.

40. Yerman HM, Holinger LD, Bronchogenic cyst with tracheal involvement. Ann Otol Rhinol Laryngol 1990; 99: 89-93.

41. Read CA, Moront M, Carangelo R, Holt RW, Richardson M. Recurrent bronchogenic cyst: an argument for complete surgical excision. Arch Surg 1991; 126: 1306-1308.

42. Beer B, Trigaux JP, Weynants P, Collard JM, Melange M. Foregut cyst of the mediastinum: fluid re-accumulation after transbronchial needle aspiration. Br J Radiol 1989; 62: 558-560. 